\title{
Understanding Internationalization: The Case of Tuskegee University
}

\author{
Thierno Thiam \\ Tuskegee University, Alabama, USA
}

\begin{abstract}
Drawing from Tuskegee University's participation in ACE's Creating Global Citizens Project, this analysis focuses on factors that strengthen and impede internationalization at Tuskegee University. Grounded in the historical trajectory of an institution, this analysis revolves around three methodological pillars: an audit of all international activities on Campus, a cross-sectional survey design, and a focus group. The findings suggest that although Tuskegee University is a significantly internationalized campus, efforts to sustain the internationalization process remain faced with challenges that revolve mainly around three critical areas: resource constraints, institutional structures, and awareness deficiency.
\end{abstract}

Keywords: international, internationalization, international education, higher education, Tuskegee University

\section{Introduction}

The purpose of this study, which originated from a partnership between Tuskegee University and the Council on American Education, is to map out internationalization at Tuskegee University. Most specifically, this study is designed to examine state of internationalization at Tuskegee University? The central question that this study seeks to address is the following: What are the factors that enhance or impede internationalization?

It is important to point out, at the outset, that internationalization has been defined in a variety of ways. Jack Knight, for instance, defines internationalization of higher education as "the process of integrating an international/intercultural dimension into the teaching, research, and service functions of the institution" (Knight, 1994).

As to the OECD (1994) definition, it refers to "the complex of processes whose combined effect, whether planned or not, is to enhance the international dimension of the experience of higher education in universities and similar educational institutions" (OECD, 1994).

The variations in the language used to define and frame internationalization, notwithstanding, the common denominator remains the reference to formal/institutional as well as informal programs and activities that have a recognizable international dimension on higher education campuses. Therefore, my study is interested in the processes toward stronger, healthier and more dynamic international engagements, activities and program within the university both at the curricular and co-curricular level.

\section{Mission, Vision and Goals}

Tuskegee University prides itself with a tradition and history of educating African Americans, albeit not

Thierno Thiam, Ph.D., Associate Professor, College of Arts and Sciences, Department of History and Political Science, Tuskegee University. 
exclusively, to prepare them for the challenges of the modern world. This pride is not a mere mission statement; it is rooted in Tuskegee University's tradition of international engagement that can be traced back to its founder, Booker T. Washington. One of the most salient symbols of such engagement is captured perhaps best by Tuskegee's involvement with the Republic of Togo. In 1901, Tuskegee's founder and first president sent a team of four scientists to Togo to help in the production of cotton in the West African nation.

Tuskegee University presidents have since committed the institution to uphold such legacy by increasing Tuskegee's global footprint. More than a century after the founding of this historic institution, a review of the state of internationalization on campus could not be any timelier and more useful not because an understanding of internationalization at this prestigious Historically Black College and University (HBCU) could prove essential as institutions of Higher Education around the country continue to grapple with the imperative of producing global citizens.

\section{The Methodological Approach}

This study rests on three major pillars - a Campus-Wide Audit of International Programs and Activities, a Series of Seven Focus Groups, and a Cross-Sectional Survey

\section{The Campus Wide Audit: Curricular, Co-Curricular Programs and Activities at Tuskegee University}

The campus wide audit, in particular, reveals that Tuskegee University is relatively a highly internationalized institution. The curriculum from all its five colleges and two schools reflects an international component that avails the Tuskegee University student body with a theoretical knowledge about the World on par with most institutions of higher learning. However, the survey and focus groups have also revealed that such theoretical understanding of the world could be made stronger by an increased effort that would include travel, study, and work abroad for students, faculty and staff.

The three instruments that are designed for the internationalization review report have also brought to the fore a good number of opportunities and challenges. They reveal that Tuskegee University has a variety of well-developed programs and partnerships. Tuskegee's international presence is quite significant and encompasses almost every single continent and two dozen countries (see below the appended detailed report by college).

The study also reveals, however, that efforts to sustain international engagements remain faced with challenges that revolve mainly around resource constraints, institutional structures, as well as an awareness deficiency.

\section{Resources Constraints}

Constraints related to access to resources are arguably the single most significant factor in efforts to internationalize further Tuskegee University. This is especially true since resources are key to every aspects of the process from international research and presentations, to recruiting and sustaining international students and faculty.

\section{Institutional Structures}

Although, various sections of the Tuskegee Campus are engaged, at different levels, with internationalization, there is a need for a clearer and more publicized delineation of the functions of each unit engaged with internationalization.

\section{Awareness Deficiency}

One of the key findings of both the survey and the focus groups is that the lack of awareness about 
international programs and activities (both curricular and co-curricular) is quite significant. This is true among students, faculty and staff both prior to joining Tuskegee University and afterwards.

\section{The Focus Group}

The background. Qualitative research methods, and focus groups, in particular, have been useful for an increased understanding of survey results (Betts, Baranowski, \& Hoerr, 1996). Focus group study is a method of group interview, which explicitly includes and uses guided group interaction to generate data (Greenhalgh \& Taylor, 1997; Powell \& Single, 1996). Group dynamics become an integral part of the process with participants engaged in discussion with each other rather than directing their comments solely to the facilitator (Catterall \& Maclaran, 1997; Templeton, 1994). Furthermore, focus groups are highly efficient use of time and resources, as data can be collected simultaneously from multiple persons (Gulunick \& Keough, 1997).

This section of the study describes the results of focus groups conducted as part of the larger study with the ultimate goal of understanding internationalization at Tuskegee University.

The specific objective of the focus groups is to explore perceptions from students, faculty and staff regarding factors that strengthen or impede internationalization at Tuskegee University.

\section{Methodology}

\section{Question Development}

The focus group questions used by the facilitator were developed through a review of the literature, and the assistance of the Tuskegee University Internationalization Team (TUIT).

\section{Participants}

Invitations to participate in the focus groups were given to students, faculty and staff attending and working on Tuskegee University's campus. Fifty five students, faculty, staff, 25 males and 30 females responded. Appropriate dates, times and locations for the sessions were confirmed with the respondents, and participants received a reminder phone call a day prior to the focus group. The study was approved by the Human Participants Review Committee of Tuskegee University.

\section{Interview Guide}

A structured interview guide with prompts and corresponding recorders/observers' guide was developed based on the procedure described by Bovell-Benjamin et al. (2009), Elmubarak and Bovell-Benjamin (2005) and Mahoney et al. (2003). The purpose of the guide was to ensure that the groups were facilitated with consistency. The guide consisted of three sections - the introduction, interview, and closure. The introduction portion of the guide outlined how to introduce oneself (facilitator) and recorders/observers, presented the purpose and procedures for the focus groups, invited participants to introduce themselves (by first names only), and outlined a rapport building exercise for the participants. The interview section consisted of questions and probes to elicit information. The closing portion of the guide prompted the facilitator to summarize points raised during the interview. Participants were given the opportunity to provide clarification and make any final comments.

\section{Procedure}

Seven focus groups of Tuskegee University students, faculty, and staff were conducted in Tuskegee, Alabama. The focus groups were organized based on gender; three male and three female focus groups were 
conducted, with six to twelve participants per group. One focus group (a pilot) to ensure logistics, question appropriateness etc. was a mixed group of males, females, students, faculty, and staff.

The same Facilitator and two recorders/observers conducted each focus group, using the interview guide. At each session, an audio-recorder (with participants' permission) was used to collect participants' detailed responses and discussions of the questions. The recorders/observers noted their observations using a structured form that followed the topics in the interview guide. The recorders/observers were asked to record the participants' facial expressions, body language, levels of enthusiasm, and other nonverbal responses as described by Renner et al. (2004).

All participants were seated in a circular fashion, and the facilitator tried to create a comfortable, supportive environment to stimulate discussion. Refreshments were provided at each session. At the start of each focus group, introductions and a rapport building exercise were done following the interview guide. The participants were again assured of confidentiality, and asked to give verbal informed consent. They were reminded of the right to refuse participation at any stage of the process and the option to withdraw from the discussion at any time. Focus group participants were encouraged to respond to the facilitator and to other members of the group freely without waiting to be called on, yet none of the participants were called on or forced to respond. The facilitator then proceeded with the predetermined questions, which were open-ended, neutrally presented, conversational, clear and concise as suggested by Kreuger and Casey (2000). The approximate time for each focus group was 60 minutes.

\section{Analysis of Transcripts}

The responses recorded on the audio- and videotapes were transcribed verbatim, a common procedure used to analyze qualitative data. Only the investigators had access to the audio-tapes. The transcripts from the facilitator and recorders/observers were compared, plus comparison to the audio-tape, and they agreed more than $98 \%$ of the time. All focus groups were transcribed and summarized, resulting in a written script for each group. The results of each focus group were analyzed and compared to describe commonalities and differences in responses across the groups. Responses were sorted, categorized, interpreted and excerpts from the transcripts were also chosen to illustrate the summary statements. The excerpts served to provide validity of the findings (Baumgartner \& Strong, 1998).

\section{Findings}

The focus group findings centered around three broad clusters: awareness, experience, and suggestions.

(1) Awareness

To the question "Are you aware are any international requirements, programs or activities (both curricular and extra-curricular) at Tuskegee?", seventeen of the fifty-five participants across groups were totally unaware. Most participants indicated that they heard about the International Student Association (ISA). Other responses are shown in Table 1.

In response to the question, "How do you normally find out about international requirements, programs or activities (curricular or extra-curricular) at Tuskegee?" Most participants indicated that the communication line was somewhat broken, but they became informed from circulating flyers, students, friends, University website, international office, international faculty, course catalog and word of mouth.

Students, faculty and staff were asked which international programs or activities were most important to them. Studying abroad was most important to the male and female students. Faculty indicated student and 
research travel, exchange programs, scholarship opportunities, awareness creation, "better communication with international students", host families and mentors for international students. More money for international programs and activities was the major concern for all groups.

Table 1

Responses- "Are You Aware Are any International Requirements, Programs or Activities (Both Curricular and Extra-Curricular) at Tuskegee?"

- Political science has some courses that address international issues

- Core curriculum- students must take World Civilizations

- All freshmen in CAENS has to take the course World, Food, Fiber and People

- Know of former student that tried to start an African Organization

- Have international students that play baseball and softball

- Do not know how the international student office works, and what they do

- High level of internationalization - a lot of diversity especially in the faculty

- Vet school at Tuskegee has an exchange program where students from the Caribbean come to Tuskegee to do clinical work

- In the Engineering Department, project with University in Egypt

- Study abroad with Burkina Faso and Costa Rica

- International seminar

This question elicited fearful body language from many participants; however, it was answered with much reservation in some groups and candidly in others. "Do you think your campus places a lot of importance on providing students with knowledge about international events, issues or other perspectives?" Of the 55 participants across groups, 22, 9 and 24 said no, yes and moderate or could do better, respectively. Responses included comments such as: "No-need link on school website that provides information about international activities, guidelines and requirements";

To the question "The school needs to do a lot more about providing information about the services provided by the international office", Table 2 shows some of the main responses.

Table 2

Responses- “What Type of International Experience Have you Had Since you Have be at Tuskegee?"

- Program sponsored by USAID- worked in Egypt with peanut and sesame

- Travel to meetings abroad

- Project in Ghana working with farmers introducing the orange and purple fleshed sweet potato

- Worked with a lot of international faculty and staff

- Worked with Neo- Liberal Globalization - goal at the end to write a book for international students

- Worked on graduate student thesis committee

- Worked on the NATO project

- International food and nutrition conferences, just being able to interact with people from other countries

- Studied abroad

- International faculty, staff and students

- Not much experience

- Travel extensively in Africa and exchange with international visitors

- Travel to Caribbean

- None

- Serbia for a research project

- Relationship with international staff, friends and faculty

- Travelled to Bangladesh and Ghana to teach

(2) Experience

Participants were asked to describe their international experiences at Tuskegee University. Many responses had mostly individualized experiences, not structured, regular programs or international activities (see Table 2). 
When asked about the international contents of their courses or jobs, most frequent answers were: none, all courses, to some extent, not much, with the exception of public health, take some French, international agriculture class, African history, not a significant extent and " $90 \%$ component of work is international" (one focus group member).

(3) Suggestions

A sample of suggestions given by participants to change, modify and improve international experiences at Tuskegee (see Table 3).

Table 3

Suggestions to Change, Modify or Enhance International Component of Experiences at Tuskegee University

- Encourage students to become more globally aware; part of curriculum, bring in guest international lectures newsletters etc.

- TU should get faculty and students more oriented. Track them from home to TU

- More communication

- Study abroad students to present; expand international presence

- More information about international programs

- Group travel for campus and community members to visit other countries

- Research various national holidays and put up banners "happy China independence day" International festivals, gift shop and seminars on campus

- Orientation for faculty and staff on international things and how they are done

- Big sister, big brother program for national and international students

- Courses for international students to sharpen language skills

- Faculty and staff to learn conversational language skills

- Exchange programs

- Enhance international office

- Encourage peers on international activity

- More information to international students

- Testimonies from international students

- Budget in place for international program, activities

- Send more student, faculty outside to recruit

- Communicate the international work that has been done

- Identify international students and have them interacting more

- Have a class for all freshmen to take educating them about international issues

- Establish contact with faculty from other universities and have student exchange program

- Travel - allow students to travel and set up link with professors and other students

- Have an international office that gives students a broad understanding of the world

Participants were asked, "How would you measure success of internationalization at Tuskegee?" Table 4 shows a snapshot of the responses.

Table 4

Responses- "How Would you Measure Success of Internationalization at Tuskegee?"

- Increase in international student's body

- Increase in the international programs/ activities

- Other international students recommending other students

- Increase in the number of students graduating

- Number of exchange programs

- Scholarships available

- Increase in time spent to do proposals - this will result in the increase in the number of international students

- Using the Tuskegee brand name to promote Tuskegee

- All of us getting what we want in terms of internationalization

- Students' awareness of international events

- When campus as a whole becomes more aware of international policies and issues

- Level of satisfaction from international students

- More student, faculty and staff participation

- Number of American students receiving international jobs 
The majority of participants across all focus groups agreed that money/budget would be needed to make internationalization on the campus a success. Other resources needed included: better communication, more education on issues of culture, more scholarships and study abroad programs. These efforts in particular would significantly contribute to reducing insularity. Finally, a conscious effort to reduce overload for faculty, accommodate international students and involve local students could result in increased internationalization.

\section{Conclusion}

Although the findings reported are very preliminary, the study identified perceptions about internationalization on the Tuskegee University campus, some of which might have been overlooked. The focus groups served as a useful tool to generate information.

\section{Cross-sectional Survey on Internationalization at Tuskegee University}

\section{Overview}

The cross-sectional survey was designed in conjunction with the audit and the focus groups as an additional tool for a better understanding internationalization at Tuskegee. As with the audit and the focus groups, the survey targeted the three essential stakeholders of the Tuskegee campus, notably students, faculty, and staff. Additionally, six key dimensions of internationalization were identify- teaching/research, resources, administration, faculty, students, and marketing. The purpose was to collect the opinions of Tuskegee's stakeholders on these six critical dimensions. The response rates were $42.2 \%$ for students, $28.1 \%$ for faculty, and $29.7 \%$ for staff.

\section{Summary of the Survey Findings}

The findings from the survey do reinforce the findings in the campus wide audit and the focus group as they point to an overall healthy internationalization at Tuskegee. The survey, however, like the audit and the focus group study does point to some lessons. The most significant of findings are threefold. Overall, factors that are likely to improve internationalization on the Tuskegee Campus, as the charts below suggest, include:

(1) More Resources devoted to a sustained internationalization campaign;

(2) A more sustained and systematic marketing campaign with a significance presence on the Tuskegee website;

(3) A more systematic effort at recruiting international students.

\section{Conclusion and Recommendations}

This study has sought to map out internationalization on the Tuskegee University campus. The central question, which this study sought to address is the following: What factors enhance or impede internationalization at Tuskegee University? To this effect, three key instruments were designed, including a campus wide audit of international programs and activities, a cross-sectional survey, and a series of seven focus groups.

The findings from this study suggest that Tuskegee University is a significantly internationalized campus as measured by its variety of well-developed programs and partnerships.

This review, however, also suggest that efforts to sustain the internationalization process at Tuskegee University remain faced with challenges that revolve mainly around three critical areas: resource constraints, institutional structures, and awareness deficiency. The nature of these constraints is discussed under the audit section and the recommendations of this committee take into account such constraints. 
It is important to point out that addressing such challenges will necessitate an integrated strategy, which will systematically seek to weave and expand international education themes in university curricular and co-curricular activities and programs.

Furthermore, continued and sustained efforts to more successfully integrate international students into the fabric of curricular and co-curricular activities on campus are bound to yield significant dividends. Specific actions on this front should include:

(1) A Study Abroad Program;

(2) An English as a Second Language (ESL) program;

(3) Mentoring programs for international students;

(4) Systematic recruitment efforts;

(5) A University-wide database for international internship programs;

(6) The creation of an International Students and Scholars Center;

(7) Partial tuition remission scholarships for international students, in return for community service (on or off campus);

(8) A Commitment from the university's senior administrators to identify and resolve strategic questions that surround the location, type, governance, and development of programs delivered to an international audience.

\section{References}

Baumgartner, T. A., \& Strong, C. H. (1998). Conducting and reading research in health and human performance (2nd ed., p. 50). Massachusetts: Mc Graw-Hill.

Betts, N. M., Baranowski, T., \& Hoerr, S. L. (1996). Recommendations for planning and reporting focus group research. J. Nutr. Edu., 28, 279-281.

Bovell-Benjamin, A. C., Dawkins, N., Pace, R. D., \& Shikany, J. (2009). Use of focus groups to understand African-Americans' dietary practices: Implications for modifying a Food Frequency Questionnaire. Prev. Med., 48, 549-554.

Catterall, M., \& Maclaran, P. (1997). Focus group data and qualitative analysis programs: Coding the moving picture as well as the snapshots. Sociological Research Online, 2(1), 1.1 Retrieved from http://www.socresonline.org.uk/socresonline/2/1/6. html

Elmubarak, E., Bromfield, E., \& Bovell-Benjamin, A. C. (2005). Focused interviews with Sudanese-Americans: Perceptions about diet, nutrition and cancer. Prev. Med., 40, 502-509.

Greenhalgh, T., \& Taylor, R. (1997). How to read a paper: Papers that go beyond numbers (qualitative research). BMJ, 315, 740-743.

Gulunick, M., \& Keough, V. (1997). Focus groups: An exciting approach to clinical nursing research. Prog Cardiovasc Nurs, 12 , 24-29.

Knight, J. (1994). Internationalization: Elements and checkpoints. Ottawa: Canadian Bureau for International Education.

Kreuger, R. A., \& Casey, M. A. (2000). Focus groups: A practical guide for applied research (3rd ed., p. 61). Thousand Oaks, C.A.: Sage Publications.

Mahoney, C. A., Lafferty, C. K., \& Nutter, S. K. (2003). Focus groups with school staff to explore asset- building innovativeness. Am. J. Health Behav., 27, 135-145.

Organisation for Economic Co-operation and Development (OECD), Centre for Educational Research and Innovation. (1994). Curriculum development for Internationalisation: Guidelines for country Case Studies. Paris: CERI/IEA.

Powell, R. A., \& Single, H. M. (1996). Focus groups. Internat J. Qual Health Care, 8, 499-504.

Renner, C. C., Patten, C. A., Enoch, C., et al. (2004). Focus groups of Y-K Delta Alaska Natives: Attitudes toward tobacco use and tobacco dependence interventions. Prev. Med., 38, 421-431.

Templeton, J. F. (1994). Focus groups: A guide for marketing and advertising professionals (pp. 10-15). Chicago: Probus. 